\title{
Research on the Development of Online Education Industry With "Suspended Class, Ongoing Learning" Strategy
}

\author{
Ying Shen
}

\author{
Zhejiang Normal University \\ SelenaPuth@outlook.com
}

\begin{abstract}
This paper firstly analyzes the short-term development of online education during the period of COVID-19's impact. In addition, the medium and long-term analysis of the industry has been made with the framework of supply and demand analysis, discussing the comparison between China and South Korea's education and the technical and policy factors on the demand side, and sums up the online teaching mode and tools on the supply side. The rapid development of China's leading enterprises of online education is reflected in constantly expanding market and in-depth segmentation of the filed. This article takes Koolearn, one of the leading enterprises, as a sample for case analysis, through statistics and calculation to draw charts. In summary, the author discusses the current situation and future trend of online education industry driven by COVID-19 in order to offer suggestions for educators.
\end{abstract}

Keywords: Online Education, COVID-19, Supply and Demand Analysis framework, Koolearn

\section{INTRODUCTION}

Due to the outbreak of COVID-19 at the beginning of 2020, China has completely called off traditional mode for education., and the policy of "suspended class, ongoing learning " has been greatly affirmed, which has also brought unprecedented online education opportunity. Online education, is a new education model that makes full use of modern information technologies such as Internet and artificial intelligence. Its broad definition includes the toC model, that is, it provides students, parents and other C-terminal users with education resources, content and services; it also includes the toB model, whose clients are public schools, education bureaus, etc., and it offers customers education information systems and technology platform services. This paper mainly focuses online education on narrow definition- toC model.

In terms of theoretical significance, as before the author's submission, there are few academic articles about COVID-19 and the online education industry, and the research content is relatively fragmented; the author uses the theoretical framework of supply and demand analysis to comprehensively discuss the development of online education. With respect to research methods, academic methods are comprehensively used such as country comparison method, data analysis method, case analysis method. So far as practical significance is concerned, the current China's online education market has been developing fast; the market size and the number of customers have been soaring. As for China's current education environment, there still exist uneven distribution of teaching resources and scarcity of high-quality resources, and online education can effectively alleviate this problem. It also promotes the education equity, contributing to inclusiveness and reduction of education costs, which are opportunities offered by COVID-19 for the education industry.

\section{THE IMPACT OF COVID-19 ON ONLINE EDUCATION}

Generally, the online education in China has an escalating trend, including the expansion of the market size of the industry and the diversification of teaching methods. Recalling the history of it, the author divides this progress into four stages: the initial germination in the late 1990s; the establishment of many magnates in the 21st century; new online teaching methods such as live broadcast and deepening subdivided fields from 2011 to 2017; since 2018, the online education industries are undergoing the "listing wave" as well as embracing multiple online teaching models [1].

At the beginning of 2020, under the impact of COVID-19, the Ministry of Education issued a policy, "suspended class, ongoing learning", stipulating the postponement of schools, such as tertiary institutions, senior high schools, primary schools, and kindergartens; and offline courses or collective activities were canceled. Both the Ministry of Education and local schools organize online courses to enable students to study online.

The author believes that COVID-19 has increased the permeability of the online education industry: the reason why online education industry previously invest a lot in advertising in summer and winter holiday is mainly because it is still in the process of completing customers' $\mathrm{s}$ 
habit cultivation and migration, rather than a game theory by entering a stock market. Because of the pause of offline education, customers like students have to passively study through the Internet, thus given the opportunity companies will accumulate users with lowest cost; in terms of policies, measures have been taken by authorities to ensure the improvement of online teaching. The dramatic growth of the demand for live coverage fully demonstrates that online education is even more popular under the impact of COVID-19. The downloads of APP growing shows that DingTalk, one of the online education platforms, has dramatically spiked since COVID-19 and ranked the second one in the real-time download rankings so far. Additionally, Qimai Data also shows that Tencent Classroom leapt from 1,046 on January 8, 2020 to No. 2 on February 9, 2020 in educational field.

\section{DEMAND-SIDE ANALYSIS OF ONLINE EDUCATION INDUSTRY}

\subsection{The demand for further education and employment: Anxiety and crisis drive the education expenditure of middle class}

East Asian culture always values education, namely, educational experience at prestigious schools is always the crucial principle of social hierarchy. The author analyzes the educational needs of China and South Korea. In China, as the family income level and the education level of parents improve steadily in the post-80s and post-90s, parents attach great importance on their children's education. As shown in FIG.1, the proportion of education consumption in household expense rises continuously. There no denying that education is a global rigid demand. With the steady growth of China's per-capita income, the sense of anxiety and crisis compresses the demand for diverse education mode, and theexpenditure on education services will continue to grow on a large scale in future [2]

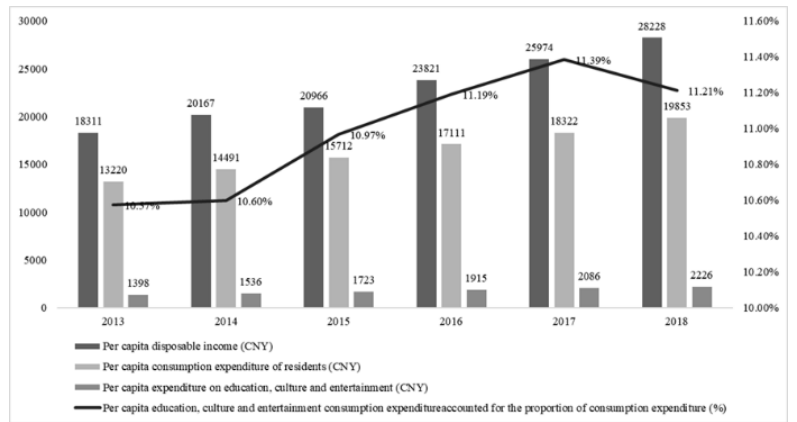

Figure 1 Per-capita disposable income and expenditure of Chinese residents in 2013-2018

\section{Source: National Bureau of Statistics}

In South Korea, the situation even more sterner than China's education environment. Unlike China, the South Korea government canceled the primary and secondary examinations for small-scale advancement, and substitute with lottery allocation, but such act further caused the burden of student tutoring; South Korea has its best universities "SKY", also the only 3 key universities. It can be seen from FIG.2 that the augment of proportion of South Korean education expenditure in junior high schools in years. So it can be inferred that families in South Korea have urgent needs for education .

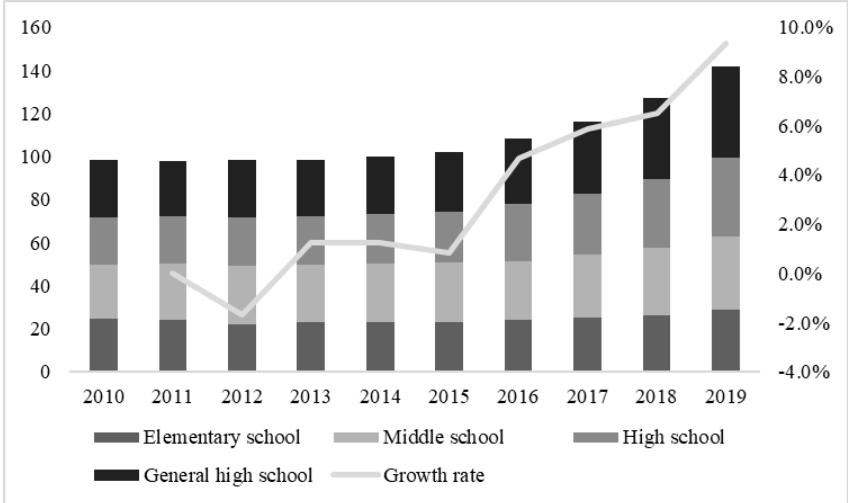

Figure 2 Average monthly private extra-curricular tuition expenditure and growth rate of Korean students in 2010-2019 (unit: 10 thousand won /\%)

\section{Source: Statistics Korea}

\subsection{Technological innovation}

With the evolution of Internet technology, advanced technologies such as AI and big data provide multiple forms for the educational experience, as well as promote in-depth the development of the Internet education platform, making it more efficient, intelligent and personalized. The author divided into 4 types: big data education; AI education; AR/VR education; online courses education. After the analyses of the report of the Ministry of Science and Technology, the authors views that artificial intelligence, big data and other technologies would continuously motivates "education + Internet" mode, and IT giants would sustain related technology research with the innovation of the industry to improve users' experience [3]. With the integration of technology and education, domestic Internet education product models now days consisted of platform, tool, content, service, and social; American education technology products can be approximately divided into products that integrate with advanced technology, learning management system products, and learning cloud systems as well as gamified learning products. Compared with domestic and international online education products, the author believes that technology has restructured the learning mode, for example, enhancing the visualization degree through the combination of hardware and software, or embedding self-creating elements to education and entertain; promoting personalized learning method or adaptive learning through the sharing of courses and timetables to ensure students' understanding of the course and the 
expansion of their communication.

\subsection{Policy enforcement: the tightening of offline training policies booms the online education}

China has formulated relevant policies to regulate offline education and stimulate online education as well. For example: the cost of running and expanding of all institutions should be increased; the "superclass" should be restricted. Although such policies cause an impact on K12 schools in short-term, there still exits a great demand of training under the pressure of further education and employment, thus for the demand side, it will not fluctuate greatly owing to changes in the supply side. Because the increasing cost of small and medium-sized institutions and the limitations of scale, high-quality online education companies and offline leading training institutions will be expected to benefit from the increased market concentration [4]. The importance of education by the state has been significantly attached. The country also has fiscal education expenditure which was 1.46 trillion CNY in 2010, and reached 3.42 trillion CNY in 2017, with an increase of $134 \%$, which mirrored China's demand for education.

\subsection{Three driving forces of huge market space for online education}

With the joint promotion of the demand for further education and employment, technological innovation and policy enforcement, the market for online education has been developing rapidly. As shown in Figure 4, according to CNNIC data, up to June 2019 , the number of online education users in China has reached 230 million, with a utilization rate of $27.2 \%$.

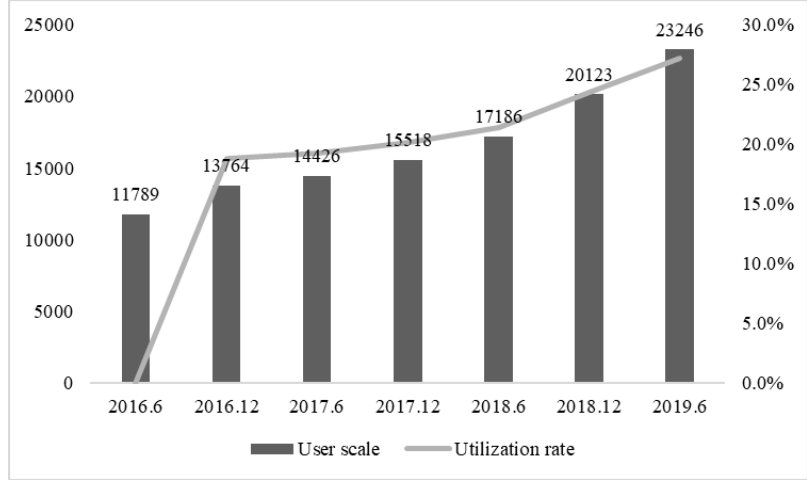

Figure 3 The scale and utilization rate of online education users in China from June 2016 to June 2019 (unit: 10 thousand people $1 \%$ )

\section{Source: CNNIC China Internet Development Statistics Survey}

\section{SUPPLY-SIDE ANALYSIS OF THE ONLINE EDUCATION INDUSTRY}

\author{
4.1. Live broadcast
}

\subsubsection{Classes}

The live broadcast model combines the advantages of traditional offline module, and mainly provides the low-price strategy to attract customers. Educational services, that is, classes are mainly broadcast live, and the teacher teaches provides real-time online interactive teaching. At the same time, students can watch the live broadcast and find out their needs. The student-teacher ratio of live classes can be as high as 100-500 while the cost of educational institutions is low. As a result, established offline training institutions and advanced Internet education such as Koolearn, TAL, Gaosiedu and Yuanfudao have successively launched low-cost courses to seize the market [5].

The marginal cost of online education is extremely low, and the granularity is more specific than offline education, which can guide various types of students to different learning modes. For example, adaptive learning or customized teaching plans which are based on students 'self-levels. Therefore, traditional training institutions with strong strength often layer their users and lay out each subdivision area, which higher the barriers to online education.

TAL repositioned IPS to create a new business form combining online and offline. As shown in Figure 4, the IPS system is part of Speiyou, which is an intelligent exercise system for offline students to match the teaching content. According to students' performance, the questions are precisely customized by the Offline + online full-scenario intelligent learning experience. In addition, TAL also launched a "dual-teacher teaching" mode to achieve the integration of online and offline advantages.

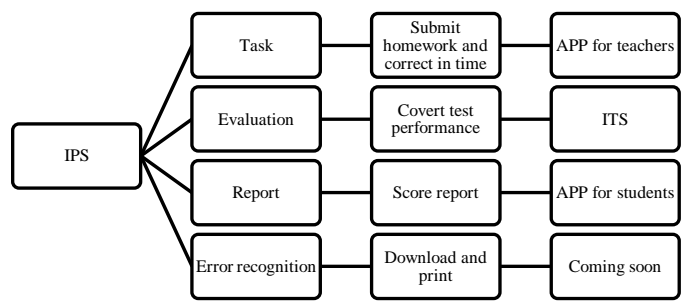

Figure 4 IPS system mind map 


\subsection{2. $1 \mathrm{~V} 1$}

1V1 live broadcast contains live-teaching methods with each teacher and one student. 1V1 live broadcast is real-time synchronized, interactive, immersive, with abundant natural experience, and intuitive teaching stimulation. As for different age stages, 1V1 live broadcast pays more attention to children's emotions and learning progress for the 0-6 year old, mainly language training; and as for the K12 group, 1V1 live broadcast provides more customized $1 \mathrm{~V} 1$ extracurricular training and language training [6].

\subsection{Recording}

Recording refers to courses that teachers record and publish on the online education platform in advance for users. The courses cover a wide range of fields, usually focusing on IT, financial training and language training.

\subsection{Tool}

\subsubsection{Items banking and homework mentoring}

Items banking includes the intelligent terminal question making. It is based on search data and feedback of students. It accurately analyzes students' performance of knowledge and uses technical means to analyze data in order to improve student learning efficiency. There is a great amount of tools, including photo search, composition search, so that students can search for the resolution steps. Homework mentoring is to complete online answers to difficult questions after class. Zuoyebang, one of the relate enterprises, was established in September 2015, which focuses on three professions: making questions, answering questions one-on-one, and online tutoring.

\subsubsection{M-school}

M-school is usually a derivative of website or APP focusing on the browsing of educational resources and the tracking of students' performance in school. Seewo is committed to promoting home-school communication by class optimization master. Teachers can immediately feedback to students on school performance through the APP, and can also assist through function settings such as reward and punishment seals, as well as to keep the relevant data of the students' comprehensive quality evaluation.

\subsection{3. $\mathrm{O} 2 \mathrm{O}$}

The $\mathrm{O} 2 \mathrm{O}$ platform mainly provides information about teachers and courses, so that customers can expediently choose types of services [7]. The industries such as Qingqing that provide tutoring platform services mainly include tutoring, etc. According the contact information which is matched to the appropriate tutoring, the platform arranges the tutoring for visiting service after obtaining the client's consent.

\section{CASE ANALYSIS OF KOOLEARN (H0094.7HK)}

\subsection{Powerful education brands and products}

\subsubsection{The only online education platform of $E D U$}

Established in 2005, Koolearn was defined as the online education platform, and it provides internally developed online education courses for in all-age students groups, mainly including three major parts: pre-school education, K12 education and university education, and educational content packages for customers.

Koolearn has provision of qualified teachers for online education by ensuring teachers that have been fostered and developed, also avoiding pain spots of the high turnover rate, and making career planning for them. Koolearn also has a content development team of about 800 experts to make sure that the content is developed internally following strict procedures, including market research, real-time data analysis, internal testing, and quality control. When developing content, Koolearn applies different approached to different parts, as shown in Table 1.

Table 1. Koolearn's content development approaches vary in different parts

\begin{tabular}{|c|c|c|c|}
\hline Products & $\begin{array}{c}\text { Graduate } \\
\text { entrance } \\
\text { exam }\end{array}$ & LBOC & Donut \\
\hline $\begin{array}{c}\text { Classifica } \\
\text { tion }\end{array}$ & $\begin{array}{c}\text { College } \\
\text { education }\end{array}$ & $\begin{array}{c}\text { K12 } \\
\text { education }\end{array}$ & $\begin{array}{c}\text { Preschool } \\
\text { education }\end{array}$ \\
\hline
\end{tabular}




\begin{tabular}{|c|c|c|c|}
\hline $\begin{array}{c}\text { Develop } \\
\text { ment } \\
\text { Strategy }\end{array}$ & $\begin{array}{l}\text { Regularly } \\
\text { update }\end{array}$ & $\begin{array}{l}\text { Cooperatio } \\
\mathrm{n} \text { with the } \\
\text { local } \\
\text { school, } \\
\text { feedback } \\
\text { from } \\
\text { students } \\
\text { and } \\
\text { teachers, } \\
\text { analyze the } \\
\text { local } \\
\text { education } \\
\text { curriculum }\end{array}$ & \begin{tabular}{l} 
Customer \\
\multicolumn{1}{c}{ survey } \\
and \\
analysis, \\
online \\
classroo \\
m \\
questionn \\
aire \\
survey \\
professio \\
nal \\
productio \\
n \\
program \\
mer, UI \\
designer \\
and video \\
director, \\
dubbing \\
and \\
recording \\
actors
\end{tabular} \\
\hline $\begin{array}{c}\text { Key } \\
\text { Results }\end{array}$ & $\begin{array}{c}\text { Latest exam } \\
\text { updates } \\
\text { andadmissi } \\
\text { on } \\
\text { information } \\
, \\
\text { Learning } \\
\text { achievemen } \\
\text { t } \\
\text { improveme } \\
\text { nt, }\end{array}$ & $\begin{array}{c}\text { Highly } \\
\text { localized } \\
\text { courses, } \\
\text { Customize } \\
\text { d courses, } \\
\text { Improveme } \\
\text { nt of } \\
\text { learning } \\
\text { efficiency }\end{array}$ & $\begin{array}{c}\text { Targeted } \\
\text { content, } \\
\text { High-qua } \\
\text { lity } \\
\text { interactiv } \\
\text { e content }\end{array}$ \\
\hline
\end{tabular}

\subsubsection{Comprehensive education product line}

\subsubsection{1. $\underline{B 2 C}$}

LOBC focuses on K12 education part, mainly providing localized interactive teaching and research courses for low-tier cities. Established in 2012, Donut was defined as a primary and secondary school education and training institution for pre-school children. Koolearn provides live broadcast courses for English learning, including English reading, vocabulary, speaking and literature, and see Figure 5 for details [8].

\subsubsection{2. $B 2 B$}

Koolearn provides packages for universities, public libraries, and public sector institutions. Additionally, it is the exclusive partner of the ETS TOEFL online practice module in China. The company purchases the TOEFL online practice module from ETS and sells it to XDF.

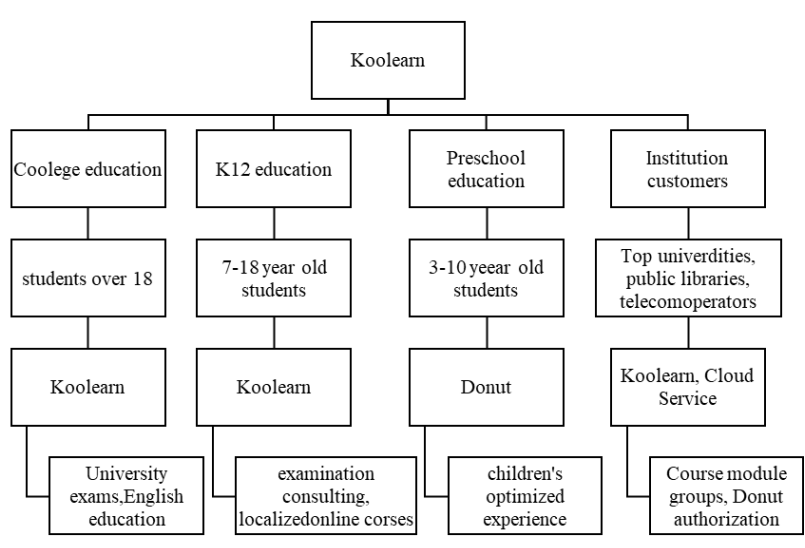

Figure 5 Koolearn's product line

\subsection{Financial business situation}

As shown in Figure 6, on January 20, 2020, Koolearn announced the half-year report for fiscal year 2020 (corresponding to 20190601-20191130). 567 million RMB in the first half of the year. Among them, research and development expenditure increased by $109 \%$ from 61.7 million RMB until November 30, 2018 to 128.9 million RMB for the six months ended November 30, 2019. From a business perspective, the proportion of $\mathrm{K} 12$ business rose to $22.6 \%$, while the proportion of university education declined, and the K12 business continued to exert its strength. As for College education: business account (revenue accounted for $63.67 \%$ ) and paying users (accounted for 40.46\%) decreased; K12's revenue accounted for $22.6 \%$, users accounted for $57.33 \%$; and pre-school branch for Donut continued to optimize, and the gross profit margin rose to $40.6 \%$.

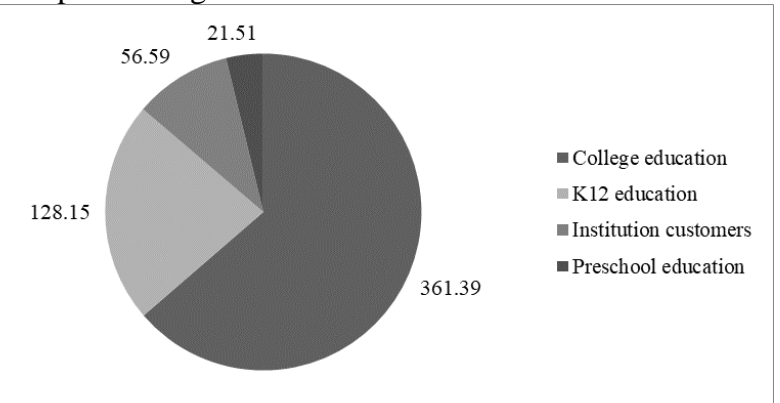

Figure 6 Operating income of Koolearn in 2019.11.30 (unit: RMB million) 


\section{CONCLUSION}

\subsection{Summary}

Aiming at the long-medium term development of the toC model of online education under COVID-19, the author uses the country comparison method and the data chart analysis method to conclude that the epidemic has not only played a role in promoting short-term profitability in the online education industry, but also enabling the industry to converse education at low cost in long-term [9]. As the huge demand side market develops, the supply side has a variety of forms and a well trend. As for the case analysis of the business income composition and development trend of the Koolearn, it can be inferred that the leading enterprises have diversified educational forms. Therefore, online education can help improve the current state of education in the country, and the epidemic has played a role in accelerating the development of online education. This paper not only analyzes the situation of online education under the influence of this epidemic, but also analyzes and predicts the future trend [10]. By analyzing the difficulties and opportunities faced by online education, it provides new research directions for China's online education and fills the academic gap.

\subsection{Expectation}

Due to space limitations, this article fails to elaborate on various cases of specific online education. In the future, the author will further analyze in this direction by analyzing the business composition and development trends of different online education industries.

\section{REFERENCES}

[1] Robin Mason. Online education using learning objects[J]. British Journal of Educational Technology, 2004, 35(6):752-754.

[2] Linda M. Harasim. Online Education: Perspectives on a New Environment[M]. Greenwood Publishing Group Inc. 1990.

[3] Jorge Larreamendy-Joerns and Gaea Leinhardt. Going the Distance with Online Education[J]. Review of Educational Research, 76(4):567-605.

[4] I. Elaine Allen, Jeff Seaman. Going the Distance: Online Education in the United States, 2011[M]. Sloan Consortium. P.O. Box 1238, Newburyport, MA 01950. Tel: 781-583-7561; Fax: 888-898-6209; e-mail: info@sloanconsortium.org; Web site: http://sloanconsortium.org, 2011.

[5] Brad Cahoon, Mark Warshauer. Electronic Literacies:
Language, Culture, and Power in Online Education[J]. Computers \& Education, 2000, 71(5):627.

[6] Chubb J E, Moe T M. Higher Education's Online Revolution[J]. Communications of the Acm, 2012.

[7] A. Frank Mayadas, John Bourne, Paul Bacsich. Online Education Today[J]. Science, 323(5910):p.85-89.

[8] Keith Kirkpatrick. Technology brings online education in line with campus programs[J]. Communications of the Acm, 2015, 58(12):17-19.

[9] Olguin G S, Souza I A D, Varella T T, et al. THE IMPACT OF DIFFERENT PRODUCTION STYLES OF VIDEOS IN ONLINE EDUCATION[J]. Gene Therapy, 2015, 8(8):579-585.

[10] Wilson M B. Online education: From classrooms to outreach, the internet is changing the way we teach and learn $[\mathrm{J}]$. Journal of the Acoustical Society of America, 2014, 136(4):2222-2222. 